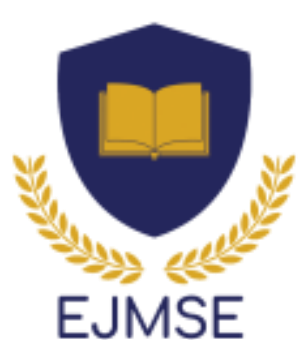

European Journal of Mathematics and Science Education

Volume 1, Issue 2, 107 - 119.

ISSN: 2694-2003

https://www.ejmse.com/

\title{
Education for Responsible Environmental Behavior: Evidence from Sri Lanka
}

\author{
Ransika De Alwis \\ National Institute of Education, SRI LANKA
}

\author{
Anthoni Durage Asoka De Silva* \\ National Institute of Education, SRI LANKA
}

Received: June 13, 2020 - Revised: September 22, 2020 - Accepted: December 14, 2020

\begin{abstract}
The present study examined the levels of four environmental dimensions; environmental awareness, attitudes towards recovery, attitudes towards recycling and environmental behavior among grade 12 students in Sri Lanka. A standard scale that has four environmental dimensions and personal information was used. Effects of gender, study stream, residential area and family income of students on each of the four environmental dimensions were determined by conducting Levene's test, Kruskal Wallis $\mathrm{H}$ test, Dunnet'sT3 test and Mann Whiteny U test using SPSS for Windows version 26. Correlation analysis was run to reveal the associations among the four environmental dimensions. A sample of 1006 grade 12 students participated in the study. Students confirmed a moderate level of awareness, attitudes and behavior towards the environment. Girls' levels in terms of all four dimensions were significantly higher than those of boys. The result strongly confirmed the impact of study stream on environmental awareness, attitudes and behavior of students. Awareness, attitudes and behavior towards environment of the rural students were at the highest level. However, no significant differences were observed among students from different family income groups. The observed weak correlation between environmental awareness and behavior confirmed that knowledge has not effectively transformed into environmental responsible behavior. Moreover, strong association could be observed between attitudes towards recycling and environmentally responsible behavior of the students. Observed positive correlations among four environmental dimensions indicate that students' perceived environmental awareness and attitudes positively influence their responsible environmental behavior. These results emphasize the importance of incorporating essential environmental concepts and learning teaching strategies into the existing school curriculum to ensure students' environmentally responsible behavior. Based on the present findings, suggestions were made for curriculum developers and educators to upgrade the existing curriculum.
\end{abstract}

Keywords: Environmental awareness, environmental attitudes, environmental behavior, senior secondary students.

To cite this article: De Alwis, R., \& De Silva, A. D. A. (2020). Education for responsible environmental behavior: Evidence from Sri Lanka. European Journal of Mathematics and Science Education, 1(2), 107-119. https://doi.org/10.12973/ejmse.1.2.107

\section{Introduction}

People from all corners of the world are seeking for a sustainable living space within the limits of gifted natural resources, by rearranging their ways and means of interacting with the planet earth. In order to develop a proper interaction behavior, human being has always tried to recognize the secrets and strengths of the environment. Environmental education has been recognized as one of the main solutions to overcome ever challenging global environmental issues. Research studies conducted in the environmental education arena have been revealed that education has a great impact on the behavior of young people towards the environment (Cottrell, 2003; Frisk \& Larson, 2011). Therefore, development of students' responsible action towards the environment would be one of the main objectives of an effective and efficient education system of any country.

At present, Sri Lanka has to tackle remarkable environmental problems. Out of those, the alarming problems are loss of bio diversity, deforestation, industrial pollution, traffic congestion and poor waste management in both urban and rural areas. In addition, Extreme weather events such as floods, prolong drought conditions, landslides associated with climate change are the other issues. Since human behavior and attitudes are implicated in a number of environmental problems, environmental conservation actions are essential for the sustainable development. Therefore, the present young generation should be made aware of their responsibilities regarding the sustainable usage of currently available

\footnotetext{
* Corresponding author:

Anthoni Durage Asoka De Silva, Department of Science, National Institute of Education, Sri Lanka. $₫$ adasoka@yahoo.com
} 
natural resources for the benefit of future generations. However, even though, education for sustainable development and sustainable lifestyles has long been recognized as a key goal of education, sufficient emphasis has not yet been paid to evaluate students' knowledge, attitudes and behavior towards the environment and upgrade the school curriculum accordingly in Sri Lanka. Thus, implementation of an appropriate general education curriculum is a necessary requirement to change in the behavior of students positively towards the environment and thereby provide their contribution to protect the environment. Therefore, curriculum developers need to pay careful attention to incorporate short-term and long-term environmental protection strategies into the curriculum and encourage students to adopt such solutions which would help to solve the existing and emerging environmental problems.

Hence, the evaluation of current knowledge, attitudes and behavior of the students about the environment would help to achieve a better perspective to upgrade the existing curriculum, pedagogy and assessment procedures. Accordingly, after completing the school education, students will be able to understand environmental problems and apply the best possible solutions to solve them.

Further, existing school curriculum in Sri Lanka does not consist of a specific subject called environmental education. Since environmental education is an interdisciplinary subject (Roth, 1992) environmental education concepts are integrated into science and other subject areas in the existing curriculum. However, there is no sufficient prior knowledge regarding environmental awareness, attitudes and behavior of school students in Sri Lanka. By considering this knowledge gap the present study aims to examine the level of awareness, attitudes and behavior towards the environment of Sri Lankan students. Grade 12 students are specially selected for the study since they are the group who are ready to enter the world of work in the near future. Bradley et al. (1999) reported that identification of young students' environmental attitudes is essential as they are to face existing and emerging environmental problems and they should possess skills needed to handle the problems and pursue appropriate solutions.

Stern (2000) claimed that the environmentally responsible behavior of students is determined by several variables, and their interactions. Furthermore, several previous studies have revealed, that gender, income and residential area as major factors affecting environmental knowledge, attitudes and behavior (Atabek-Yigit et al., 2014; Veisia et al., 2018). The current study further attempts to reveal the effect of gender, study stream, place of residence and family income of grade 12 students on their awareness, attitudes and behavior towards the environment. The study also targets to determine whether there are relationships among awareness, attitudes and degree of engagement in environment related activities of grade 12 students. In this research, students' attitudes towards environment are categorized into two groups; attitudes towards recovery and attitudes towards recycling. More precisely, the current study addresses the following research questions:

1. What are students' levels of overall awareness, attitudes and behavior (AB) towards environment, environmental awareness (EA), attitudes towards recovery (AR1), attitudes towards recycling (AR2), and environmental consciousness and behavior (EB)?

2. What is the effect of gender, study stream, place of residence, and family income on $A B, E A, E R 1, E R 2$, and EB?

3. What are the relationships among students' EA, ER1, ER2 and EB?

\section{Literature review}

Education system is a key factor and it has a vital role in transferring environmentally friendly values, attitudes and skills from generation to generation (Frisk \& Larson, 2011; Roth, 1992). In the United Nations Educational, Scientific and Cultural Organization- United Nations Environment Program (UNESCO-UNEP, 1978) Tbilisi conference declaration, the objectives of environmental education have been clearly emphasized as; an awareness and sensitivity to the environment and its related problems, a basic understanding of the environment and related problems, feeling of concern for the environment and actively participating in environmental protection, skills for identifying and solving environmental problems and active involvement in solving environmental problems. Accordingly, environmental education has been viewed as an important approach to develop knowledge, attitudes and behavior towards the environment.

Further, the development of students' positive attitudes and behavior towards the environment is crucial to face existing and emerging environmental challenges and assure a sustainable society (Stevenson, 2007). By following educational programs at schools, students develop their knowledge as well as attitudes leading to the environmental friendly behavior (Petocz \& Dixon, 2011). Koruoglu et al. (2015) revealed the effect of demographic factors namely gender, grade and parents' level of education on high school students' environmental awareness, attitude and behavior. In contrast Digby (2013) argued that socio demographics had relatively little influence on environmental behaviors. without doubt, irresponsible human behavior creates many environmental problems. However, predicting environmentally significant behavior is complex and it depends on a wide range of variables (Stern, 2000). Previous researches (Owusu et al., 2017; Shanmuganathan \& Karpudewan, 2015) claimed that having an adequate knowledge about environment provides a platform to protect and retain a sustainable environment. Similarly, Kaiser et al. (2008) reported that environmental knowledge forms the base for a positive attitude towards environment and then serves as 
a motivational force to engage in environmentally responsible life style. Furthermore, individuals' interest and knowledge about environmental issues are key factors for environmentally significant behaviors (Campbell-Arvai, 2015; Owusu et al., 2017). Mobley et al. 2010 also claimed that individual's knowledge of environmental problems, their reasons and concerns are important determinant of environmental friendly behavior.

Further, Ramsey and Rickson (1976) has reported about conventional linear model that claimed, increased environmental knowledge leads to positive attitudes towards the environment which in turn leads to behavioral modifications for the betterment of environment. According to Stern (2000) knowledge itself is not enough to change individuals' attitudes or behavior. In response, Hines et al. (1987) proposed many other factors that affect environmental responsible behavior. According to Hines' model knowledge of issue, knowledge of action strategies and action skills are the determinants of responsible environmental behavior. The model further explains that individual personality factors; locus of control, attitudes, personal responsibility and situational factors such as economic constraints, social pressures and opportunities to select different actions significantly affect the environmental behavior. Later, Hungerford and Volk (1990) further developed the Hine's model, in which variables that contribute to change the environmental behavior have been divided into three categories; entry level variables, ownership variables and empowerment variables. The major variable of entry level category is sensitivity to the environment while personal commitment and deep understanding of environmental issues are major components of the ownership variables. Empowerment variables provide individuals a sense of ability to act in an environmentally responsible way. Since some of these variables can be taught, careful attention could be paid to empowerment variables in the environmental education arena (Goldman et al., 2020).

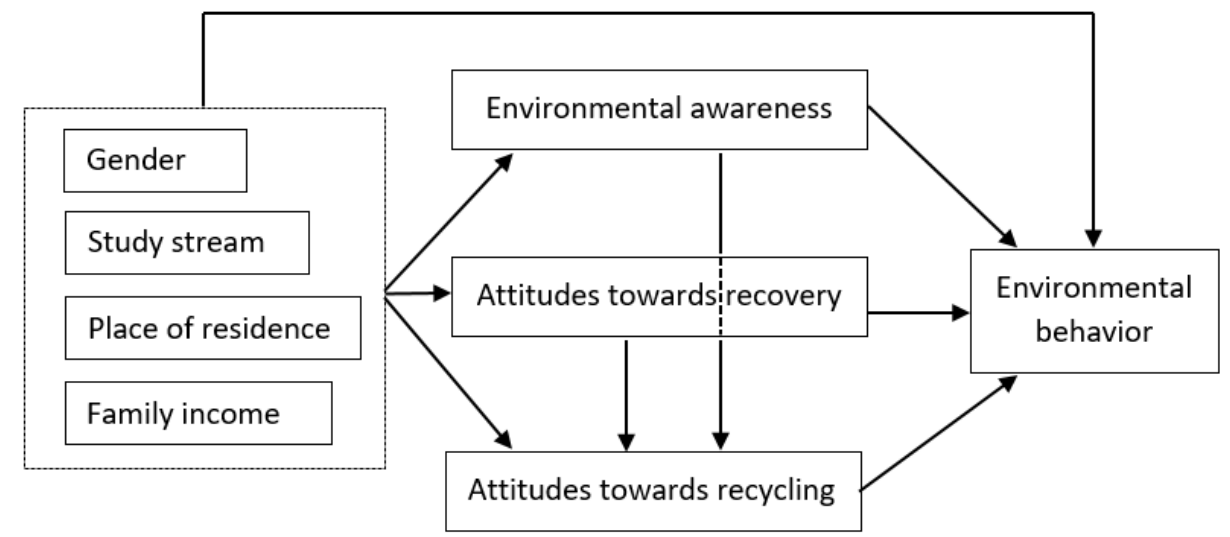

Figure 1: Conceptual Framework of the Study

Based on the literature review, the conceptual framework shown in Figure 1 was developed to illustrate the relationship between variables to be examined in the current study. Variables of interest are shown in the rectangles while associations to be tested are shown by arrows.

\section{Methodology}

\section{Survey Instrument:}

For the present study quantitative method based on the survey design was applied. The scale developed by Ugulu et al. (2013) to test high school students' attitudes towards environment and its application was adopted as the survey instrument of the current study. The scale is composed of 35 self-assessment items. Content validity and face validity of the original scale have been extensively tested by a panel of experts in the scale development process while construct validity has been examined using factor analysis with varimax rotation. Cronbach's alpha was used to check the internal consistency of each dimension of the original scale. The reliability coefficient of each dimension; EA, AR1, AR2, EB and overall scale was reported as $0.84,0.78,0.70,0.70$ and 0.83 respectively (Ugulu et al., 2013). The scale consists of 15,8 , 7 and 7 items under the dimensions EA, AR1, AR2 and EB respectively.

A 5- point Likert-type scale (1 - strongly disagree and 5 - strongly agree) was used under each item to measure individual's level of EA, AR1, AR2 and EB. Several items of the questionnaire were assessed by reversed score. The dimension EA covers planting work, environmental cleaning, importance of species, protection of forests and national parks, cultural environment, and environmental economy. The second dimension, AR1 consists of items covering the usage of rechargeable batteries, recycling old clothes and newspapers, and unconscious consumption. The third dimension consists of items namely educating people on recycling, in-house separating of waste materials for recycling, and participating in and performing recycling activities. The fourth dimension explores the direct engagement in environmental activities namely enrolling environmental projects, working voluntarily for a better environment, practicing good waste management behaviors and selecting ecofriendly products. In addition, the scale also consists of 
a section dealing with socio demographic namely gender, study stream, place of residence, and family income of the respondents.

After obtaining the authors' permission to use the original questionnaire which is available in English for the current study, it was translated into vernacular languages, Sinhala and Tamil separately. In the process of translation, two native speakers of Sinhala and Tamil who are fluent in English translated the questionnaire into two respective languages. The translated versions were translated back to English by two other language experts who were blind to the original English version. The original version and the back translated versions were examined and minor changes were made in the Sinhala and Tamil versions so that they are compatible with the local context. A panel of four senior environmental experts evaluated the content validity of the translated questionnaires. The content validated questionnaires were administered to 50 Sinhala medium and 35 Tamil medium students of grade 12 in a pilot study. Then the reliability of EA, AR1, AR2, EB and the overall scale of Sinhala medium questionnaire in terms of Cronbach's alpha were determined as $0.66,0.73,0.75,0.86$ and 0.85 respectively. Similarly, the reliability of EA, AR1, AR2, EB and the overall scale of Tamil medium questionnaire in terms of Cronbach's alpha were determined as $0.71,0.68,0.62,0.84$ and 0.81 respectively.

\section{Sample:}

The population of interest was Sri Lankan public school secondary students who were studying in grade 12 in 2020. The sample comprised of students from randomly selected 21 educational zones representing all nine provinces of the country. One class of grade 12 students representing art, commerce, science and technology streams were chosen from randomly selected 27 Sinhala medium and 9 Tamil medium schools. Though the numbers of art, commerce and science students are higher than the technology students at the national level, the number of technology students was higher than the numbers of students from the other streams in the sample. There were three groups of students in terms of the place of residence representing urban, suburban, and rural areas. The categorization of urban and rural areas in Sri Lanka has been done according to population density, firewood dependence and well water dependence (Weeraratna, 2016). Questionnaires were administered during normal school hours and participants were asked to complete them in the classroom. After rejecting incompletely filled questionnaires, 1006 completed questionnaires were remained. Out of those 1006 respondents 529 were female and 477 were male.

The demographic profile of the students participated in the study is given in Table 1.

Table 1. The Demographic Profile of the Sample

\begin{tabular}{llcc}
\hline Variable & Description & $\mathbf{N}$ & $\mathbf{\%}$ \\
\hline \multirow{2}{*}{ Gender } & Male & 477 & 47.41 \\
& Female & 529 & 52.58 \\
\hline \multirow{3}{*}{ Study stream } & Art & 199 & 19.78 \\
& Commerce & 111 & 11.03 \\
& Science & 228 & 22.66 \\
& Technology & 468 & 46.52 \\
\hline \multirow{2}{*}{ Place of residence } & Urban & 92 & 9.14 \\
& Suburban & 324 & 32.20 \\
\multirow{2}{*}{ Monthly family income (USD) } & Rural & 590 & 58.64 \\
& Above 750 & 28 & 2.78 \\
& 250-750 & 357 & 35.48 \\
& Below 250 & 621 & 61.72 \\
\hline
\end{tabular}

\section{Analysis of data:}

The quantitative research design was used in this study to explore the environmental awareness, attitudes and behavior of grade 12 students in Sri Lanka. The study aimed to examine the level of AB and its' dimensions of the respondents. The study also aimed to find whether the tested key demographic factors of the respondents affect the $A B$ and its dimensions; EA, AR1, AR2 and EB. Moreover, the relationships among EA, AR1, AR2 and EB were also determined. Data gathered by the execution of questionnaire were analyzed by applying Levene's test, Kruskal Wallis test, Dunnet'sT3 test and Mann Whiteny U test using SPSS for Windows version 26.

For the 35 items in the questionnaire, the maximum score that a student can earn is 175 and the minimum is 35 , which is an indicator of the level of students' AB. Similarly, for each dimension; EA, AR1, AR2 and EB the maximum and the minimum scores students can earn are 75-15, 40-8, 25-5 and 35-7 respectively. To interpret the students' level of $A B$, EA, AR1, AR2 and EB, according to scores they obtained for each dimension of the questionnaire, following categorization was used. It includes four levels namely very low, low, moderate and high with respect to the score earned (Table 2). 
Table 2. Score Categories Used to Interpret the Level of $A B, E A, A R 1, A R 2$ and $E B$.

\begin{tabular}{lcl}
\hline Dimensions & Score & Level \\
\hline \multirow{2}{*}{ Environmental awareness } & $15-29$ & Very low \\
& $30-44$ & Low \\
& $45-59$ & Moderate \\
Attitudes towards recovery & $60-75$ & High \\
& $8-15$ & Very low \\
& $16-23$ & Low \\
Attitudes towards recycling & $24-31$ & Moderate \\
& $32-40$ & High \\
\hline & $5-9$ & Very low \\
Environmental consciousness and behavior & $10-14$ & Low \\
& $15-19$ & Moderate \\
& $20-25$ & High \\
\hline & $7-13$ & Very low \\
Overall awareness, attitudes and behavior & $14-20$ & Low \\
& $21-27$ & Moderate \\
& $28-35$ & High \\
\hline
\end{tabular}

\section{Results}

Level of awareness, attitudes and behavior towards environment

Students' earned 132.51, 56.9, 30.11, 18.79 and 26.72 scores for AB, EA, AR1, AR2 and EB respectively. According to the above categorization (Table 2) students confirmed a moderate level of AB, EA, AR1, AR2 and EB. Calculated mean scores for each dimension of interest are shown in Table 3.

Table 3. Students' Mean Score and Level of AB, EA, AR1, AR2 and EB

\begin{tabular}{lccccc}
\hline Dimensions & N & $\begin{array}{c}\text { Number } \\
\text { of items }\end{array}$ & Mean & SD & Interpretation \\
\hline Environmental awareness & 1006 & 15 & 56.90 & 5.84 & Moderate \\
Attitudes towards recovery & 1006 & 8 & 30.11 & 5.03 & Moderate \\
Attitudes towards recycling & 1006 & 5 & 18.79 & 3.75 & Moderate \\
Environmental consciousness and behavior & 1006 & 7 & 26.72 & 5.17 & Moderate \\
Overall awareness, attitudes and behavior & 1006 & 35 & 132.51 & 14.38 & Moderate \\
\hline
\end{tabular}

The highest and the second highest mean values showed for EA and AR1 sub dimensions while lowest and second lowest values for AR2 and EB dimensions.

\section{Overall awareness, attitudes and behavior towards environment in relation to gender}

The study examined the $\mathrm{AB}$ towards the environment in relation to gender. Levene's test was run to test equality of variance. Accordingly, equality of variances assumptions was not met. Hence, nonparametric Mann-Whitney U test was run to test if there was a significant difference in terms of gender in AB, EA, AR1, AR2 and EB. As the $p$ value (<.05) of the test was significant, it was found that grade 12 female students had a significantly higher level of $A B$ towards the environment than that of the male students (Table 4). 
Table 4. Comparison of Overall Awareness, Attitudes and Behavior towards Environment with Regard to Gender

\begin{tabular}{|c|c|c|c|c|c|c|}
\hline Dimension & Gender & $\mathbf{N}$ & $\begin{array}{l}\text { Number of } \\
\text { items }\end{array}$ & $\begin{array}{l}\text { Mean } \\
\text { Rank }\end{array}$ & Effect Size & $\begin{array}{l}\text { Sig. (2- } \\
\text { tailed) }\end{array}$ \\
\hline \multirow[t]{2}{*}{ Environmental awareness } & Male & 477 & 15 & 480.39 & \multirow{2}{*}{0.006} & \multirow{2}{*}{$.015^{*}$} \\
\hline & Female & 529 & & 524.34 & & \\
\hline \multirow[t]{2}{*}{ Attitudes towards recovery } & Male & 477 & 8 & 467.74 & \multirow{2}{*}{0.014} & \multirow{2}{*}{$000 *$} \\
\hline & Female & 529 & & 535.74 & & \\
\hline \multirow[t]{2}{*}{ Attitudes towards recycling } & Male & 477 & 5 & 469.69 & \multirow{2}{*}{0.012} & \multirow{2}{*}{$000 *$} \\
\hline & Female & 529 & & 533.99 & & \\
\hline \multirow{2}{*}{$\begin{array}{l}\text { Environmental consciousness and } \\
\text { behavior }\end{array}$} & Male & 477 & 7 & 465.57 & \multirow{2}{*}{0.015} & \multirow{2}{*}{$000^{*}$} \\
\hline & Female & 529 & & 537.71 & & \\
\hline \multirow{2}{*}{$\begin{array}{l}\text { Overall awareness, attitudes and } \\
\text { behavior }\end{array}$} & Male & 477 & 35 & 458.83 & \multirow{2}{*}{0.021} & \multirow{2}{*}{$000^{*}$} \\
\hline & Female & 529 & & 543.78 & & \\
\hline
\end{tabular}
${ }^{*} \mathrm{p}<.05$

Furthermore, female students showed a significantly higher levels of scores for all the dimensions; EA, AR1, AR2 and EB compared to their counterparts. Effect size for Mann-Whitney $U$ test as the $\eta^{2}$ based on z statistics is also given.

\section{Overall awareness, attitudes and behavior towards environment in terms of study stream}

Students level of $\mathrm{AB}$ towards environment with respect to study stream is shown in Table 5. According to the data analysis, science students showed the highest score, while art, commerce and technology students showed second highest, third highest, and the lowest scores respectively. To test if there are significant differences in $A B$ towards environment with respect to study stream, at first, Levene's test was run to test equality of variance. According to the results of Levene's test, equality of variances assumptions was not met, hence, Kruskal Wallis $H$ test was run. The $\rho$ value of the test $(<.05)$ revealed that at least one pair of study streams differed from each other in terms of $A B$ towards environment. Dunnett's T3 test was applied to identify the pairs which were significantly different from each other. Those pairs and effect size for Kruskal Wallis $H$ test as the $\eta^{2}$ based on H statistics are also shown in the Table 5.

Table 5. Comparison of Students' Overall Awareness, Attitude and Behavior towards Environment with Respect to Study Stream

\begin{tabular}{lccccl}
\hline Study stream & $\mathbf{N}$ & Mean Rank & Sig. & Effect Size & Different pairs \\
\hline Art & 199 & 492.31 & .000 & 0.048 & Art-Science \\
Commerce & 111 & 484.49 & .000 & & Commerce-Science \\
Science & 228 & 621.32 & .000 & & Science-Technology \\
Technology & 468 & 455.37 & & \\
Total & 1006 & & & & \\
\hline The mean different is significant at the 0.05 level & & &
\end{tabular}

Statistically significant differences in $\mathrm{AB}$ towards environment were observed between the pairs; art-science, commerce-science and science-technology. However, no significant difference was observed between the pairs; artcommerce, art-technology and commerce-technology. The existence of significant differences among four dimensions; EA, AR1, AR2 and EB with respect to study streams was also tested separately by applying the procedure described above. The $\rho$ value of the Kruskal Wallis H tests for EA, AR1, AR2 and EB $(<.05)$ revealed that at least one pair of study streams differed from each other in terms of EA, AR1, AR2 and EB. Dunnett's T3 test was applied to identify the pairs which were significantly different from each other.

Comparison of students' environmental awareness with respect to study stream

Dimension EA showed similar results in relation to AB towards environment against study stream (Table 6).

Table 6. Comparison of Environmental Awareness with Respect to Study Stream

\begin{tabular}{lccccl}
\hline Study stream & $\mathbf{N}$ & Mean Rank & Sig. & Effect Size & Different pairs \\
\hline Art & 199 & 430.06 & .000 & 0.064 & Art-Science \\
Commerce & 111 & 416.70 & .000 & & Commerce-Science \\
Science & 228 & 631.07 & .000 & & Science-Technology \\
Technology & 468 & 493.17 & & \\
Total & 1006 & & & & \\
\hline
\end{tabular}

The mean different is significant at the 0.05 level 
EA of science students is the highest. Statistically significant differences were observed between the pairs; art-science, commerce-science and science-technology (Table 6). However, significant differences were not observed between the pairs; art-commerce, art-technology and commerce-technology.

Comparison of students' attitudes towards recovery with respect to study stream

Table 7 presents the students' AR1 with respect to study stream. Science students showed the highest mean while technology students showed the lowest.

Table 7. Comparison of Attitudes towards Recovery with Respect to Study Stream.

\begin{tabular}{lccccl}
\hline Study stream & N & Mean Rank & Sig. & Effect Size & Different pairs \\
\hline Art & 199 & 515.58 & .000 & 0.012 & Science -Technology \\
Commerce & 111 & 490.96 & & & \\
Science & 228 & 561.94 & & & \\
Technology & 468 & 472.87 & & & \\
Total & 1006 & & & & \\
\hline
\end{tabular}

The mean different is significant at the 0.05 level

Comparison of students' AR1 dimension with respect to study stream revealed significant difference between science and technology streams only (Table 7). However, difference between the pairs; art-commerce, art-science, arttechnology, commerce-science and commerce-technology are not statistically significant.

Comparison of students' attitudes towards recycling with respect to study stream

Table 8 presents AR2 with respect to study stream. Science students earned the highest score while technology students earned the lowest score.

Table 8. Comparison of Attitudes towards Recycling with Respect to the Study Stream

\begin{tabular}{lccccl}
\hline Study stream & $\mathbf{N}$ & Mean Rank & Sig. & Effect Size & Different pairs \\
\hline Art & 199 & 517.11 & .036 & 0.044 & Art-Science \\
Commerce & 111 & 542.96 & .002 & & Art-Technology \\
Science & 228 & 596.88 & .011 & & Commerce-Technology \\
Technology & 468 & 442.87 & .000 & & Science-Technology \\
Total & 1006 & & & & \\
\hline \multicolumn{2}{l}{ The mean different is significant at the 0.05 level }
\end{tabular}

As given in Table 8 comparison of students' AR2 dimension with respect to the study stream revealed significant differences between the pairs: art-science, art-technology, commerce-technology and science-technology streams. However, significant differences were not observed between the pairs: art-commerce, and commerce-science streams.

Comparison of students' environmental consciousness and behavior with respect to the study stream

As shown in Table 9 students' EB with respect to the study stream, science students showed the highest score while technology students showed the lowest score.

Table 9. Comparison of Environmental Consciousness and Behavior with Respect to the Study Stream

\begin{tabular}{|c|c|c|c|c|c|}
\hline Study stream & $\mathbf{N}$ & Mean Rank & Sig. & Effect Size & Different pairs \\
\hline Art & 199 & 548.31 & .000 & 0.030 & Art -Technology \\
\hline Commerce & 111 & 545.86 & .000 & & Commerce-Technology \\
\hline Science & 228 & 559.48 & .000 & & Science - Technology \\
\hline Technology & 468 & 447.13 & & & \\
\hline Total & 1006 & & & & \\
\hline
\end{tabular}

The mean different is significant at the 0.05 level

Comparison of students' EB dimension with respect to the study stream revealed significant differences between the pairs; art-technology, commerce-technology and science-technology streams (Table 9). However, significant differences were not observed between the pairs; art-commerce, art-science and commerce-science streams. 
Overall awareness, attitudes and behavior with respect to place of residence

Students' AB towards environment with respect to place of residence is given in Table 10. Students from rural areas obtained the highest score. And students from sub urban areas earned the second highest score while students from urban areas obtained the lowest score.

Table 10. Comparison of overall Awareness, Attitudes and Behavior towards Environment with Respect to Place of Residence

\begin{tabular}{lccccc}
\hline Residential area & N & Mean Rank & Sig. & Effect Size & Different pairs \\
\hline Urban & 92 & 438.33 & .043 & 0.004 & Rural-Urban \\
Sub urban & 324 & 494.93 & & & \\
Rural & 590 & 518.37 & & & \\
Total & 1006 & & & & \\
\hline
\end{tabular}

The mean different is significant at the 0.05 level.

To test if there are significant differences in $\mathrm{AB}$ towards environment with respect to place of residence Kruskal-Wallis $H$ test was run. The $\rho$ values of Kruskal-Wallis $H$ test $(<.05)$ revealed that at least one pair of study streams differs from each other. Dunnett's T3 test was applied to identify the pairs which were significantly different from each other. The difference in $\mathrm{AB}$ towards environment between rural and urban students is statistically significant. Those pairs and effect size for Kruskal Wallis $\mathrm{H}$ test as the $\eta^{2}$ based on $\mathrm{H}$ statistics are also shown in the Table 10.

Furthermore, Kruskal-Wallis $H$ test was employed to test differences within four dimensions; EA, AR1, AR2 and EB with respect to the place of residence separately. Only in EA dimension the $\rho$ value of Kruskal-Wallis $H$ test $(<.05)$ revealed that at least one pair of places of residence differs from each other. Dunnett's T3 test was applied to identify the pairs which were significantly different from each other.

Table 11. Comparison of Environmental Awareness with Respect to Place of Residence

\begin{tabular}{lccccc}
\hline Residential area & $\mathbf{N}$ & Mean Rank & Sig. & Effect Size & Different pairs \\
\hline Urban & 92 & 412.03 & .005 & 0.009 & Rural-Urban \\
Sub urban & 324 & 503.52 & & & \\
Rural & 590 & 517.75 & & & \\
Total & 1006 & & & & \\
\hline
\end{tabular}

* The mean difference is significant at the 0.05 level.

As shown in Table 11 students from rural and urban areas showed significant difference in EA.

Overall awareness, attitudes and behavior towards environment in relation to the monthly family income of the student The study examined the $\mathrm{AB}$ towards the environment in relation to monthly family income of the students. The results are shown in Table 12.

Table 12. Overall Awareness, Attitudes and Behavior towards Environment with Respect to the Monthly Family Income of the Student

\begin{tabular}{lccc}
\hline \multicolumn{1}{c}{ Monthly Family Income (USD) } & N & Mean Rank & Sig. \\
\hline Over 750 & 28 & 490.68 & .168 \\
Between 250-750 & 357 & 490.68 & \\
Below 250 & 621 & 526.68 & \\
Total & 1006 & & \\
\hline
\end{tabular}

To test if there were significant differences in $A B$ towards environment with respect to the monthly family income of the students Kruskal Wallis $\mathrm{H}$ test was run. The $\mathrm{p}$ value of the test revealed that there were no significant differences among three groups (Table 12).

Relationships among the environmental awareness, attitudes towards recovery, attitudes towards recycling and environmental consciousness and behavior

Finally, a Bivariate Spearman's correlation analysis was done to reveal the relationships among the dimensions; EA, AR1, AR2 and EB. Results are shown in Table 13. 
Table 13. Correlation among Environmental Awareness, Attitudes towards Recovery, Attitudes towards Recycling and Environmental Consciousness and Behavior of Students

\begin{tabular}{lcccc}
\hline Dimensions & $\begin{array}{c}\text { Environmental } \\
\text { awareness }\end{array}$ & $\begin{array}{c}\text { Attitudes } \\
\text { towards } \\
\text { recovery }\end{array}$ & $\begin{array}{c}\text { Attitudes } \\
\text { towards } \\
\text { recycling }\end{array}$ & $\begin{array}{c}\text { Environmental } \\
\text { consciousness } \\
\text { and behavior }\end{array}$ \\
\hline Environmental awareness & 1 & $.219^{* *}$ & $.203^{* *}$ & $.201^{* *}$ \\
Attitudes towards recovery & & 1 & $.487^{* *}$ & $.416^{* *}$ \\
Attitudes towards recycling & & & 1 & $.657^{* *}$ \\
Environmental consciousness and behavior & & & & 1 \\
\hline
\end{tabular}

**. Correlation is significant at the 0.01 level (2-tailed).

The correlations between each pair of dimensions EA-AR1, EA-AR2, and EA-EB of grade 12 students were weak but positively correlated with the $\mathrm{r}$ values $0.219,0.203$, and 0.201 respectively. The analysis also revealed positive correlations between the pairs of dimensions; AR1-AR2 and AR1-EB of grade 12 students at a moderate level with the $r$ values 0.487 and 0.416 respectively. However, the association between the pair of dimensions; AR2-EB was a strong positive correlation with the r value of 0.657 .

\section{Discussion}

The results revealed a moderate level of AB, EA, AR1, AR2 and EB of Sri Lankan senior secondary students. Sachithra and Kaluarachchi (2018) reported a low level of environmental literacy of Bachelor of Commerce undergraduates in Sri Lanka. By administering the same instrument used in the current study, Koruoglu et al. (2015) reported that attitudes towards environment of a sample of Turkish high school students was at a low level. Frisk and Larson (2011) and Nunez and Clores (2017) reported the students' moderate level of environmental literacy and environmental knowledge and behavior. In the current study, students showed the highest score for the dimension EA, while the second highest for the dimension AR1. Concepts related to the dimensions EA and AR1 have been incorporated into the secondary school curriculum in Sri Lanka. As senior secondary school students enter Grade 12 class just after sitting for the General Certificate of Education (Ordinary Level) Examination which is a high-stake national level examination, their knowledge regarding the dimensions EA and AR1 would be at a higher level. However, students showed the lowest score for the dimension AR2 while the second lowest level for the dimension EB. Concepts coming under the dimensions AR2 and EB are mostly associated with the activities to be performed in the real life, rather than mere recalling facts. Further, those items are to check students' capabilities of transferring the knowledge and skills that they gained from the school education into the real-world applications. According to the results, it is evident that transformation of knowledge regarding environmental concepts into practice is weak among Sri Lankan senior secondary school students. For sustainable behavioral change, Frisk and Larson (2011) suggested the importance of incorporating diverse environmental concepts into the curriculum. Furthermore, students need to be exposed to specific real- life learning experiences or in other words authentic learning experiences that nourish their development of attitudes towards environment and transform those attitudes into environment friendly actions.

Performance differences in male and female students have been reported in Sri Lankan education system for many years (NEREC, 2008, 2013, 2015, 2016). The present study confirmed that female students participated in the study have statistically significant higher level of AB and its' dimensions; EA, AR1, AR2 and EB compared to their male counterparts. Previous studies have reported that secondary school girls' science performance is higher than that of the boys in Sri Lanka (NEREC 2013, 2015). With the scale used in the present study Koruoglu et al. (2013) have also revealed that Turkish female high school students had a higher level of environmental attitudes compared to their counterparts. De Silva et al. (2019) reported that grade 11 girls' science performance and motivation towards learning science were higher than that of the boys in Sri Lanka. Girls' higher level of AB towards environment revealed in the present study may be a consequence of their higher science performance and higher motivation towards learning science as reported by De Silva et al. (2019). In the Sri Lankan context, girls' commitment, hardworking behavior and enthusiasm might make them more aware of environmental problems and change their attitudes in a positive manner. Finally, the developed awareness and attitudes would have been transformed into environment responsible actions. According to Sachithra and Kaluarachchi (2018), however, undergraduate male students had a significantly higher level of engagement in environmental activities compared to their female counterparts. This group of students are not representing a general cross section of senior secondary school students as these undergraduates are the group representing high performers at the General Certificate of Education (Advanced Level) Examination, which is a national level high-stake examination held to select students for the placement in the public universities.

As per the present study, students in the science stream showed a significantly higher level of awareness, attitudes and behavior towards the environment than arts, commerce and technology students in $\mathrm{AB}$ as well as in its dimensions; EA, AR1, AR2 and EB. On the other hand, technology students were at the lowest level in AB as well as in its dimensions taken into consideration in the current study. A possible reason for these results could be that students in the science stream who are thoroughly taught the concepts regarding the environment, may possess more knowledge regarding the environmental protection than the students of the other streams. They may also have participated in the detailed 
discussions about existing environmental issues and protection measures with their colleagues and teachers as a part of their coursework. Other possible reason could be that students in the other streams may be less interested in learning about the environment related topics though they are included in art, commerce and technology curricula which are more scientific in nature. If art, commerce and technology students are facilitated understand the importance of being aware of the environmental issues through authentic learning experiences such as project work, they would develop environment friendly attitudes and behaviors. This result raises the importance of inculcating environment education concepts in every possible subject areas of the curriculum at each grade. Although, environment related topics such as natural cycles, climate changes and impact of human activities on natural environment have been already included in the technology curriculum, exam-oriented, teacher-centered passive learning teaching practices may be the reason for the technology students' lower level of awareness, attitudes and behavior towards the environment. The researchers have eye witnessed that the subject matters are just transmitted to the students ignoring the importance of giving them authentic experiences. Therefore, teachers should take students outside the classroom and expose them to acquire knowledge and skills need to take appropriate measures to overcome environmental issues. Moreover, students need to be encouraged to participate in public awareness programs outside the school and assigned projects to solve the real-world environmental problems. Students need to understand that a little positive change in individuals' behavior makes huge positive contribution to the protection of environment. Further, the study highlighted the importance of integrating environment related topics in different subject areas of the curriculum and selecting suitable learning teaching approaches which nourish the expected awareness, attitudes and skills of the students.

The study further examined the differences in $A B$ towards environment with regard to the students' place of residence. Students living in rural areas showed significantly higher level of AB than students in urban areas. Lower level environmental awareness, attitudes and behavior towards environment of urban students may occur as students in urban areas have less interactions with the natural environment, they are attending overcrowded schools in the city and they are under higher academic pressure due to parents' influence on exam oriented academic activities compared to their counter parts in rural areas. In line with this results Davis et al. (2006) pointed out the importance of having interaction with nature to develop environmental friendly values. Cheng and Monroe (2012) suggested that students' childhood interaction with nature have shown a great influence on their intention to participate in nature friendly activities in the latter part of their lives. Cheng and Monroe (2012) also suggested that the students who have got more nature related experiences would be more committed to protect it, while others who have had less nature experiences paid more care about themselves over the nature. They also confirmed students' connections with nature was a strong predictor of their environmental friendly actions in the future. Some other researches have also provided supporting evidence for the fact that interactions with nature began at the early stages of children's life had a positive influence on nourishing positive attitudes and behavior towards the environment in their adulthood (Chawla \& Cushing, 2007; Wells \& Lekies, 2006). However, Sachithra and Kaluarachchi (2018) reported that undergraduate students' environmental practices were not affected by residential area. According to the previous research, Sri Lankan urban students' performance in science, mathematics and English language was much higher than that of the rural students (NEREC, $2015,2016)$. However, the reason for the grade 12 rural students' higher level of awareness, attitudes and behavior towards environment would be due to their more nature based experiences such as caring for nature, commitment to protect nature and enjoyment of nature in their home environment.

The study also examined the effect of students' family income on environmental awareness, attitudes and behavior. According to the results, students from middle income families showed the highest level of environmental awareness, attitudes and behavior compared to their counterparts from lower and higher income families though the difference is not statistically significant. However, some researches have reported that people with higher income had more positive environmental attitudes and knowledge (Franzen \& Meyer, 2010; Levy et al., 2016). The current study supports the fact that Sri Lankan students' family income has no significant impact on students' awareness, attitudes and behavior towards environment.

Finally, the study examined the correlation between four dimensions; EA, AR1, AR2 and EB. The findings revealed weak positive correlation between the dimensions; EA-AR1, EA -AR2 and EA-EB (Table 19). The weak positive correlation confirmed that EA as a type of knowledge, does not directly influence on AR1, AR2 or EB. On the other hand, the results showed moderate positive correlation between the pairs of dimensions AR1-AR2 and AR1-EB. Accordingly, attitude toward recovery, such as efficient energy consumption, using ecofriendly products and reuse of household materials positively impact on attitude towards recycling habits including ecofriendly packaging, disseminating knowledge about recycling, separating waste materials and practicing proper waste disposal methods. Hence, the moderately positive correlation confirmed that students' AR1, AR2 and EB have been supporting each other. Further, the results revealed a strong positive correlation between AR2 and EB. Accordingly, the results highlight that if the students have positive attitudes towards recycling they tend to perform environment friendly behaviors such as conserving water, selecting environmentally harmless products, commitment for livable environment and proper recycling habits. However, previous studies have confirmed that students who had deeper knowledge about environment had shown strong sensitivity and attitudes towards the environment but they had not reproduced their knowledge into positive behaviors towards the environment (Nunez \& Clores, 2017; Yumuşak et al., 2016). Similarly, Garcesa and Limjuco (2014) pointed out that their respondents who had more knowledge on environment related concepts showed less 
ability to transform their knowledge into practice. Finally, the correlation between focused dimensions revealed that students' environmental responsible behavior can be motivated by nurturing their EA, AR1 and AR2. Therefore, it is worth to note the significance of designing the curriculum by in-cooperating the essential components of environmental knowledge and attitudes such a way that students get opportunities to develop environmentally responsible actions and conservation ethics.

\section{Conclusion}

In the existing school curriculum, environmental education has a narrow focus, but it should be broad enough to achieve sustainable environmental protection of the country. Curriculum developers and teachers should consider specific strategies to integrate environment related concepts into formal and non-formal school curriculum in order to facilitate young generation of Sri Lanka to achieve a higher level of environmental knowledge, attitudes and behavior. On the other hand, it is obvious that incorporating each and every environmental protection concept in the school curriculum is impossible. Hence, it is important to introduce an array of strategies which enhance students' environmental responsible actions. Accordingly, the curriculum needs to be upgraded further, incorporating new concepts to develop environmental knowledge, attitudes and skills. Establishing environmental clubs in the schools and creating links between school, environmental authorities, and other relevant organizations working towards the betterment of the environment may worth to strengthen environmental education. Another possible option would be getting the involvement of volunteer regional environmental well-wishers who possess updated environmental knowledge, attitudes and behavior with the classroom activities. The research inspires the importance and need of further research in the future with regard to the students' awareness, attitudes and behavior towards environmental protection.

\section{Recommendations}

The research recommends curriculum developers to incorporate environment related outdoor projects and activities that provide real world environmental experiences to develop students' attitudes and behavior. Moreover, it is recommended to conduct qualitative research such a case studies and action research to get a deeper understanding about students' attitudes and behaviors towards the environment. Impact of students' cultural, religious, and school background toward environmental behavior is open for further research.

\section{Limitations}

Although environmental behavior is influenced by many other factors, the current study focused only on few selected demographic factors. For the present study students were selected from the schools offering senior secondary education in art, commerce, science and technology streams. That means selected schools are bigger schools with a large number of students enjoying more facilities compared to the other public schools offering only art and/or commerce streams.

\section{References}

Atabek-Yigit, E., Koklukaya, N., Yavuz, M., \& Demirhan, E. (2014). Development and validation of environmental literacy scale for adults (ELSA). Journal of Baltic Science Education, 13(3), 425-435.

Bradley, J., Waliczek, T., \& Zajicek, J. (1999). Relationship between environmental knowledge and environmental attitude of high school students. Journal of Environmental Education, 30(3), 17-22.

Campbell-Arvai, V. (2015). Food-related environmental beliefs and behaviors among university undergraduates: A mixed-methods study. International Journal of Sustainability in Higher Education, 16(3), 279-295.

Chawla, L., \& Cushing, D. (2007). Education for strategic environmental behavior. Environmental Education Research, $13(4), 437-452$.

Cheng, J. C. H., \& Monroe, M. C. (2012). Connection to nature: Children's affective attitude toward nature. Environment and Behavior, 44(1), 31-49.

Cottrell, S. P. (2003). Influence of sociodemographics and environmental attitudes on general responsible environmental behavior among recreational boaters. Environment and Behavior, 35(2), 1-29. https://doi.org/10.1177/0013916503251439

Davis, B., Rea, T., \& Waite, S. (2006). The special nature of outdoors: Its contribution to the education of children aged 311. Journal of Outdoor and Environmental Education, 10, 3-12.

De Silva, A. D. A., Khatibi, A., \& Azam, S. M. F. (2018). Do the demographic differences manifest in motivation to learn science and impact on science performance? Evidence from Sri Lanka. International Journal of Science and Math education, 16(1), 47-67.

Digby, C. L. B. (2013). The influences of socio-demographic factors, and non- formal and informal learning participation on adult environmental behaviors. International Electronic Journal of Environmental Education, 3(1), 37-55. 
Franzen, A., \& Meyer, R. (2010). Environmental attitudes in cross-national perspective: A multilevel analysis of the ISSP 1993 and 2000. European Sociological Review, 26(2), 219-234.

Frisk, E., \& Larson, K. L. (2011). Educating for sustainability: competencies and practices for transformative action. Journal of Sustainability Education, 2(1), 1-20.

Garcesa, R. D., \& Limjuco, R. (2014). Environmental literacy and integration of environment issues among science teachers in region XI: Basis for training design. UIC Research Journal, 20(1), 187-205. https://doi.org/10.17158/554.

Goldman, D., Hansmann, R., Cincera, J., Radovic, V., Telesiene, A., Balzekiene, A., \& Vavra, J. (2020). Education for environmental citizenship and responsible environmental behavior. In A. C. Hadjichambis, P. Reis, D. P. Hadjichambi,J. Cincera, J. B. Pauw, N. Gericke, \& M. C. Knippels, Conceptualizing Environmental Citizenship for 21st Century Education (pp.115-137). Springer Nature Switzerland AG. https://doi.org/10.1007/978-3-030-20249-1.

Hines, J. M., Hungerford, H. R., \& Tomera, A. N. (1987). Analysis and synthesis of research on responsible environmental behavior: A meta-analysis. Journal of Environmental Education, 18(2), 1-8.

Hungerford, H. R., \& Volk, T. L. (1990). Changing learner behavior through environmental education. Journal of Environmental Education, 21(3), 8-21.

Kaiser, F. G., Roczen, N., \& Bogner, F. X. (2008). Competence formation in environmental education: advancing ecology specific rather than general abilities. Environmental Psychology/Umweltpsychologie, 12(2), 56-70.

Koruoglu, N., Ugulu, I., \& Yorek, N. (2015). Investigation of high school Students' environmental attitudes in terms of some demographic variables. Psychology, 6, 1608-1623.

Levy, A., Orion, N., \& Leshem, Y. (2016). Variables that influence the environmental behavior of adults. Environmental Education Research, 24(3), 307-325. https://doi.org/ 10.1080/13504622.2016.1271865

Mobley, C., Vagias, W. M., DeWard, S. L. (2009). Exploring additional determinants of environmentally responsible behavior: The influence of environmental literature and environmental attitudes. Environment and Behavior, 42(4), 420-447. https://doi.org/10.1177/0013916508325002

National Education Research and Evaluation Centre. (2008). National Assessment of achievement of grade 8 students of 2007 in Sri Lanka. Colombo University Press.

National Education Research and Evaluation Centre. (2013). National Assessment of achievement of grade 8 students in Sri Lanka - 2012. Colombo University Press.

National Education Research and Evaluation Centre. (2015). National Assessment of achievement of students completing grade 8 in year 2014 in Sri Lanka. Colombo University Press.

National Education Research and Evaluation Centre. (2016). National Assessment of Achievement of Students Completing Grade 8 in Year 2016 in Sri Lanka. Colombo University Press.

Nunez, M. B., \& Clores, M. A. (2017). Environmental literacy of K-10 student completers. International Journal of Environmental \& Science Education, 12(5), 1195-1215.

Owusu, G. M. Y., Kwakye, T. O., Welbeck, E. E., \& Ofori, C. G. (2017). Environmental literacy of business students in Ghana. International Journal of Sustainability in Higher Education, 18(3), 415-435.

Petocz, P., \& Dixon, P. (2011). Sustainability and ethics: graduate dispositions in business education. Asian Social Science, 7(4), 18-25.

Ramsey, C. E., \& Rickson, R. E. (1976). Environmental Knowledge and Attitudes, The Journal of Environmental Education, $8(1), 10-18$.

Roth, C. E. (1992). Environmental literacy: Its roots, evolution and directions in the 1990s. ERIC Clearinghouse for Science, Mathematics and Environmental Education.

Sachithra, K. M. V., \& Kaluarachchi, D. G. P. (2018). Educating for environmental practices: An assessment from bachelor of commerce (B. Com) undergraduates in Sri Lankan state universities. Vidyodaya Journal of Management, 4(2), 2749.

Shanmuganathan, S., \& Karpudewan, M. (2015). Modeling environmental literacy of Malaysian pre - university students. International Journal of Environmental \& Science Education, 10(5), 757-771.

Stern, P. C. (2000). Toward a coherent theory of environmentally significant behavior. Journal of Social Issues, 56(3), 407-424. 
Stevenson, R. B. (2007). Schooling and environmental education: Contradictions in purpose and practice. Environmental Education Research, 13(2), 139-153. https://doi.org/10.1080/13504620701295726

Ugulu, I., Sahin, M., \& Baslar S. (2013). High school students' environmental attitude: scale development and validation. International Journal of Educational Sciences, 5(4), 415-424.

United Nations Educational, Scientific and Cultural Organization- United Nations Environment Program. (1978). Recommendations of the Intergovernmental Conference on Environmental Education. The Tbilisi Declaration.

Veisia, H., Lacyb, M., Mafakheria, S., \& Razaghia, F. (2018). Assessing environmental literacy of university students: A case study of Shahid Beheshti University in Iran, Applied Environmental Education \& Communication, 18(1), 25-42. https://doi.org/10.1080/1533015X.2018.1431163

Weeraratne, B. (2016). Re-defining urban areas in Sri Lanka (Working paper series 23). Institute of Policy Studies of Sri Lanka. https://www.ips.lk/re-defining-urban-areas-in-sri-lanka/

Wells, N. M., \& Lekies, K. S. (2006). Nature and the life course: Pathways from childhood nature experiences to adult environmentalism. Children, Youth and Environments, 16(1), 1-24.

Yumuşak, A., Sargın, S. A., Baltacı, F., \& Kelani R. R. (2016). Science and mathematics teacher candidates' environmental knowledge, awareness, behavior and attitudes. International Journal of Environmental \& Science Education, 11(6), 1337-1346. 